\title{
IUSNATURALISMO, POSITIVISMO Y NECESIDADES BÁSICAS: UNA LECTURA DE LA OBRA DEL PROFESOR ERNESTO GARZÓN VALDÉS *
}

\author{
Luis Manuel Sánchez \\ Universidad Nacional de San Agustín (Arequipa, Perú)
}

RESUMEN. La crítica del iusnaturalismo es usualmente dirigida contra el carácter anterior, absoluto, inmutable y superior, que esta corriente predica del Derecho natural. Es posible que esta crítica no valore suficientemente la necesidad de distinguir entre las variedades de iusnaturalismo, algunas de las cuales podrían resistir tales cargas. Ése podría ser el caso de un iusnaturalismo que se remita simplemente a las circunstancias de las necesidades básicas, o naturales, de las personas, para pensar el Derecho. La obra reciente del profesor E. GARZÓN VALDÉs, sugiere una aproximación de este tipo, aunque proviene de una matriz principalmente positivista y de seguro el profesor resistiría el intento de ser ubicado como re-constructor de algún tipo de Derecho natural. Este artículo explora ciertas implicaciones del punto de vista de GARZÓn, partiendo de saldar algunas cuentas del debate entre positivismo jurídico y Derecho natural.

Palabras clave: E. GARZÓN VALDÉS, necesidades básicas, iusnaturalismo.

ABSTRACT. Criticism against natural law is usually directed against the previous, absolute, immutable and superior character attributed to natural law. Such criticism possibly does not distinguish among the varieties of natural law theories, some of which may resist such attacks. This might be the case of a natural law theory simply based upon people's basic-natural needs from which the law may be derived. Professor E. GARZÓn VALDÉs's recent works suggest a viewpoint like this, although surprisingly developed within the tradition of positivism, and for sure the professor would refuse being sorted as a natural law re-constructor. This article explores some implications of GARzón's argument, starting from a balance of the traditional debate between positivism and natural law.

Keywords: E. GARZÓn VALDÉs, basic needs, natural law theory.

\footnotetext{
* Fecha de recepción: 28 de octubre de 2010. Fecha de aceptación: 30 de noviembre de 2010.
} 
n el artículo «La naturaleza de la cosa del año 1970», E. GARZÓN VALDÉS recuerda que en la segunda mitad del siglo XX a las corrientes iusnaturalistas se les ha hecho varios reproches. Entre ellos, la equivocidad manifiesta del concepto «Derecho natural», el carácter abstracto de las asunciones de las que parten, el peligro de indoctrinación que portan y la imposibilidad empírica de la existencia de un sistema normativo supralegal ${ }^{1}$. GARZÓN añade a esas críticas otras que dirige contra las doctrinas, particularmente alemanas, de la «naturaleza de la cosa», debidas a autores como COING, SCHAMBEK, MAIHOFER, entre otros, y contra la teoría de las «estructuras lógico-objetivas» de H. WeLZEL. En su conjunto, las objeciones que el profesor argentino reúne contra el iusnaturalismo en el artículo citado podrían resumirse en las siguientes:

a) La ambigüedad de los conceptos que los autores iusnaturalistas emplean.

b) La dificultad para precisar cuál es el contenido de la «naturaleza de la cosa».

c) La postulación de un Derecho que se asume absoluto e inmutable.

d) Tales doctrinas constituirían un retorno teórico al punto de vista anterior a HumE y KANT y a tener que admitir ontologías de carácter metafísico.

e) Tales doctrinas presumen que detrás de las realidades jurídicas habría otras realidades por descubrir.

f) Equivalen a atribuir Derecho a las condiciones fácticas.

g) Afirman la creencia de que la biología cuenta para el Derecho.

b) Incurren en un salto deductivo al pretender derivar del ser las condiciones del deber ser.

i) Reducen la tarea del legislador a un mero conocimiento en el que no intervendría la voluntad.

j) En cuanto la «naturaleza de la cosa» es referida la justicia, linda con una versión ideológica, ya que la justicia se parece más a una ideología.

k) El iusnaturalismo habría servido también para justificar el hitlerismo.

l) La doctrina de la «naturaleza de las cosa» es, últimadamente, de contenido emotivo.

Es necesario advertir desde el inicio que varias de las críticas reseñadas no serían totalmente suscritas en la teoría más reciente del destacado pensador argentino. Desde hace varias décadas GARZÓN VALDÉS reflexiona sobre los significados sustantivos de los ordenamientos democráticos, y su aporte puede apreciarse, en lo medular, como una propuesta para reelaborar las conexiones entre la democracia y algunos aspectos de la moral vinculados con el reconocimiento de los derechos y las necesidades. Este punto de vista podría vislumbrarse todavía débil en las críticas que acabamos de enumerar. La razón para partir de ellas no se debe entonces a que expresen el pensamiento actual de GARZÓN, sino a que de algún modo ellas resumen las objeciones más serias que se le han hecho a las tradicionales doctrinas del Derecho natural.

La revisión de esas críticas nos servirá en este ensayo para reflexionar sobre la actualidad de los argumentos dirigidos contra el iusnaturalismo, en contraste con algunos argumentos importantes que pueden dirigirse contra el positivismo jurídico.

1 E. GARZÓN VALDÉs, «La naturaleza de la cosa (1970)», en Derecho, ética y política, Madrid, Centro de Estudios Constitucionales, 1993, 61. 
Veremos en el trayecto, caminando de la mano de la exposición y los desarrollos ulteriores de GARZÓN, cómo algunos de los cuestionamientos contra el iusnaturalismo se desploman, otros se reafirman, y otros pueden volverse singularmente contra el positivismo legal, su enemigo teórico favorito. En medio de ello el concepto de necesidades básicas emerge como un puente entre el Derecho y ciertas condiciones naturales, lo que parecería aproximar la teoría a ciertas instancias del Derecho natural, aunque el profesor GARZÓN no se ocupa de esclarecer este aspecto.

Adelantamos que la discusión no se propone inducir al lector a tomar partido por alguna de las posiciones en disputa. Lo que primariamente intenta es extender una invitación para repensar el Derecho sin vernos obligados a sacrificar su sustancia, evitando las disyuntivas forzadas en las que puede habernos colocado el pensamiento jurídico heredado.

\section{AMBIGÜEDADES Y HETEROGENEIDADES}

1.1. La objeción más frecuente que se hace al conjunto de teorías llamadas iusnaturalistas, mencionada por GARZÓN, tiene que ver con la ambigüedad del término.

Es evidente la dificultad de hablar del iusnaturalismo como una teoría homogénea. Con razón A. PASSERIN D'ENTREVES decía que aunque hay una historia del Derecho natural que puede rastrearse desde los filósofos estoicos, no puede negarse las grandes diferencias que hay entre el pensamiento estoico y el Derecho natural cristiano, por ejemplo ${ }^{2}$. «Cuán cerca las nociones de Derecho natural Estoica y Cristiana puedan parecer la una de la otra - escribe D'ENTREVES - hay indudablemente diferencias sutiles y de largo alcance entre ellas, derivadas de diferentes ideales y visiones de la vida» ${ }^{3}$. Además, «Las concepciones medieval y moderna de Derecho natural son dos diferentes doctrinas; la continuidad entre ellas es principalmente una cuestión de palabras» ${ }^{4}$.

D'ENTREVES hace entonces una distinción entre la «historia» y la «filosofía» del Derecho y sugiere que sólo la filosofía, y no la historia, podría proporcionar una base para trabajar la unidad entre las varias corrientes iusnaturalistas ${ }^{5}$. No es extraño, entonces, que E. BODENHEIMER agrupe a estas tendencias en tres variantes con grandes diferencias entre ellas, aunque a veces los autores las tratan indistintamente: el Derecho natural estoico, el Derecho natural cristiano y el Derecho natural clásico ${ }^{6}$. Ahora, si la existencia de estas tres variantes expresa algún grado de ambigüedad, lo propio tendría que decirse de la expresión «positivismo jurídico» que podría connotar algo distinto si se refiere a alguna de las variedades del realismo legal, al normativismo kelseniano, al formalismo de autores como SCARPELLI, o a las variedades más recientes de positivismo axiológico, soft positivismo, etcétera ${ }^{7}$.

2 A. P. D’EnTReves, Natural Law. An Introduction to Legal Philosophy, London, Hutchinson University Library, 1967 (1951), 35.

3 Ibid.

${ }^{4}$ Id., 11.

${ }^{5}$ Id., 7,8 y 12.

${ }^{6}$ E. Bodenheimer, Teoría del Derecho, México D. F., Fondo de Cultura Económica, 1990 (1940), 125-190.

7 Sobre las variedades de positivismo, vid. M. ATIENZA, «El Derecho como argumentación», en M. ATIENZA y L. FERRAJOLI, Jurisdicción y argumentación en el Estado constitucional de Derecho, México, Instituto de 
Por otro lado, no deja de ser válido preguntarse si éstos son casos de ambigüedad en el concepto de iusnaturalismo, o de diversidad de objetos comprendidos en el término. Tengamos en cuenta que aunque los conceptos buscan referirse a un ente unidimensional, esta unidimensionalidad no siempre coincide con la existencia de objetos completamente homogéneos. Los conceptos pueden referirse a una propiedad común a múltiples objetos, como por ejemplo los conceptos de la física (masa o velocidad); o a un grupo de cosas que comparten al menos una característica común relevante, por ejemplo las fuentes del Derecho positivo ${ }^{8}$. Pueden también aludir a una familia de objetos, por ejemplo las familias botánicas — las que por supuesto incluyen plantas que no son totalmente idénticas-, o hacer referencia a un grupo de cosas heterogéneas pero que tienen algún tipo de compatibilidad entre ellas, por ejemplo el concepto de comunidad o el de nación que incluyen cosas tan diversas como la población, el territorio, el Estado, etc. Es seguro que pueden proponerse otras modalidades conceptuales, además?.

De acuerdo con eso, pensamos que podría predicarse de la ambigüedad del concepto de iusnaturalismo si esta palabra no pudiese ser ubicada en alguno de los casos que acabamos de referir. Si por ejemplo no pudiera probarse que las teorías a las que el término alude no comparten al menos una característica común relevante, o si existe algún tipo de incompatibilidad insalvable entre las teorías agrupadas. De otro modo lo que tendríamos es una familia de teorías diversas, incluso heterogéneas, sin embargo identificables en sus caracteres comunes y en sus diferencias, y por ello discutiblemente ambiguas.

Lo que es cierto también es que algunas elaboraciones conceptuales pueden tener un elemento de afinidad débil en la medida en que se construyen sobre una cualidad poco relevante de los objetos comparados. Éste podría ser el caso de las varias teorías reunidas bajo el término iusnaturalismo, cuyo vínculo de identidad más importante parece definirse por oposición al positivismo. En lo que todas estas corrientes coinciden es en sostener que hay otro Derecho, diferenciable del Derecho positivo, que además sería previo y superior a éste ${ }^{10}$. Luego de esa afirmación, la unidad iusnaturalista se fracciona y cada variante pasa a hacer referencia a su propia fuente de Derecho previo, sea ésta imaginada divina, racional o naturalista (en un sentido que podría atribuirse a los pensadores antiguos). La dificultad con la expresión iusnaturalismo estaría entonces en su diversidad; pero quizás no tanto en su ambigüedad.

Podemos suponer, además — como creía CRISIPO en la antigüedad—, que las palabras con uno y sólo un significado son extraordinariamente raras en un lenguaje natural, al margen de las convenciones lingüísticas estipuladas por necesidades técnicas

Investigaciones Jurídicas, 2005, 16, 26. También, R. A. SHINER, Norm and Nature, The Movements of Legal Thought, Oxford, Clarendon Press, 1992.

${ }^{8}$ Las fuentes del Derecho son instancias heterogéneas, pero son reconocidas como tales porque comparten la característica de originar algún tipo de Derecho.

9 Hay que aceptar también que los conceptos son sólo herramientas del pensamiento para organizar la comprensión del mundo, y no hay una sola forma de construirlos. Todo está en que nos pongamos de acuerdo en criterios de conceptualización que correspondan con alguna propiedad relevante de los objetos del mundo, y que esos criterios sean suficientemente explícitos para todos.

${ }_{10}$ F. M. TAYLOR, «The Law of Nature», The ANNALS of the American Academy of Political and Social Science, 1891, 1, 559-560. 
de algún tipo. El argumento de la ambigüedad podría ser dirigido, entonces, contra la mayoría de las palabras en uso; sin embargo lo que este razonamiento realmente advierte es que la ambigüedad que a menudo se predica de las palabras puede no residir tanto en las palabras mismas, sino en el uso descontextualizado que ocasionalmente se hace de ellas.

Si se piensa la palabra «naturaleza» en abstracto, uno quedaría perplejo por la gran cantidad de significados que se asocian a ella; pero si pienso en esta palabra frente a un aviso que dice «disfrute la naturaleza de la Amazonia», la ambigüedad rápidamente desaparece. En cambio la ambigüedad retorna si en una discusión acerca de la naturaleza humana alguien afirma que «la naturaleza del hombre es ser racional en virtud de la naturaleza divina». Pero entonces la ambigüedad no se debe tanto a la palabra, cuanto al uso descontextualizado que el hablante hace de la misma. Se podría avanzar entonces a descartar ambigüedades si se logra mantener el sentido y la consistencia en el contexto en el que las palabras se usan, o en el contexto en que éstas son leídas.

El caso es el mismo si se prefiere hablar de iusnaturalismo en términos de la «naturaleza de las cosas». Ciertamente no hay una sola «naturaleza de la cosa». La palabra naturaleza hace referencia a muchas cosas, como escribe GARZÓN ${ }^{11}$. Sin embargo, eso no descarta que las varias naturalezas no puedan tener algo en común, ni que puedan ser identificables y eventualmente describibles, aun cuando las varias naturalezas pudiesen constatarse en el ámbito de un mismo objeto. Además, el que haya varias naturalezas no elimina que la naturaleza pueda ser asumida como fuente de Derecho, tan luego como su existencia heterogénea sea real y pueda ser evidenciada. ¿Es que acaso necesitamos que la naturaleza sea una sola para que sea tomada en cuenta?

Pensamos que el mérito suficiente para que la naturaleza cuente es su existencia; su variedad sólo plantea la necesidad de considerar las diferencias. Esto no excluye de por sí que la naturaleza pueda ser vista como cierto tipo de referente para las elaboraciones normativas, de manera análoga a las tecnologías que son derivadas de las observaciones físicas. En un mundo de naturalezas diversas la tarea de derivar implicancias normativas para cada contexto posiblemente se haga más compleja, pero nada indica que en tal caso la naturaleza no cuenta, ni que esta sea una actividad ilegítima, innecesaria o imposible.

\section{LA NATURALEZA EN EL IUSNATURALISMO}

2.1. El siguiente cuestionamiento al iusnaturalismo se relaciona con su postulación de un Derecho preexistente que es pensado absoluto, eterno e inmutable ${ }^{12}$. Este argumento afecta especialmente al iusnaturalismo de base teológica y quizás al de base racionalista, este último en el punto que otorga a ciertos postulados de la razón una condición de validez universal y de absoluta permanencia por encima de las sociedades, como podría ser el iusnaturalismo de LOCKE o de KANT ${ }^{13}$. No obstante es posible

\footnotetext{
11 E. GarZón VALdÉs, op. cit., 65, 69.

12 Id., 47-48.

13 Cfr. F. M. TAYLOR, loc. cit., 565.
} 
que la objeción afecte menos al Derecho natural antiguo cuyo punto de referencia, en general, no es un mundo ideal e inmutable más allá de la physis, o por encima del mundo de las cosas existentes que se asumen naturales, aun cuando ese mundo pueda ser atribuido en sus orígenes a una deidad. Ahora, si a continuación se acepta que el mundo de las cosas existentes es dinámico y cambiante, no resultaría entonces inevitable, para un cierto iusnaturalismo de tinte naturalista, la tendencia a petrificar la naturaleza en un cuerpo de leyes inmutables.

La crítica al iusnaturalismo como doctrina de lo absoluto surte pleno efecto, entonces, cuando éste es defendido como un cuerpo de leyes cósmicas eternas, ubicadas por encima de los hechos y de las que depende el Derecho. Ésta puede haber sido una visión generalizada en los primeros periodos de la Ilustración, influenciada por el concepto newtoniano de ley natural, pero no es un punto de vista defendible en nuestros días.

Si las leyes sociales fuesen «leyes» en el sentido de la física, y gobernasen por sí mismas, no habría entonces forma de impedir que operen y sólo quedaría dejarlas actuar. Ése por supuesto no es el caso en un mundo en el que la libertad de acción es siempre una posibilidad. El mundo físico se debe a las regularidades inherentes a los procesos materiales, y las sociedades, a las normas aprobadas por las personas para su propio gobierno. Sin embargo esto tampoco significa que las sociedades no tengan vínculo con la naturaleza, ni que las leyes hechas por los hombres no deban tomar en cuenta las regularidades del mundo físico del que las comunidades humanas también forman parte.

2.2. El profesor GARZÓN sostiene, por otro lado, que las doctrinas recientes de la «naturaleza de la cosa» constituirían una vuelta de la teoría al estado anterior a HumE y KANT.

«Después de KANT — indica el profesor- es difícil hablar de un Derecho natural que formaría parte de una "naturaleza cósmica", de un orden inscripto por Dios o por la naturaleza en la natura rerum, en la natura objecti del universo. Precisamente el concepto de naturaleza, como esencia situada en la trascendencia de la cosa en sí queda fuera del conocimiento racional» ${ }^{14}$.

La crítica de GARZÓN es evidentemente certera contra las tradiciones del iusnaturalismo escolástico que sitúan el Derecho natural en la naturaleza divina. En cambio deja en pie al iusnaturalismo que BODENHEIMER denomina clásico, o racionalista, el cual debe mucho en su orientación principal, precisamente a las enseñanzas de KANT. Quizás tampoco toca a las variantes que por ahora estamos llamando naturalistas, que se guían por las circunstancias de hecho, particularmente de la naturaleza física de las personas para imaginar el Derecho. A menos que aceptemos que la naturaleza física deba ser tratada como la «cosa en sí» que KANT consideraba inescrutable.

Lo mismo podría decirse de la condena al iusnaturalismo por suponer que detrás de las realidades jurídicas, o de las instituciones que expresan el Derecho, tendría que haber realidades «esenciales» que al jurista le correspondería descubrir. La objeción es efectiva en este caso contra el iusnaturalismo teológico y racionalista, pero igualmente débil frente al iusnaturalismo de sesgo naturalista. Podría dirigirse, por

${ }^{14}$ E. GarZÓn ValdÉs, op. cit., 45. 
ejemplo, contra la corriente alemana de la jurisprudencia de conceptos, por suponer que el Derecho puede reducirse a la plenitud de los conceptos, los cuales tendrían una suerte de existencia eterna en un mundo como el de las ideas de PLATón. En cambio deja intactas a las variantes naturalistas inclinadas a encontrar razones para el Derecho en el mundo de los hechos naturales observables, o por lo menos en el mundo de los hechos que estas corrientes consideran «naturales». Eso nos lleva a la siguiente crítica.

2.3. Algunas versiones de iusnaturalismo pueden desembocar en atribuir cualidades de Derecho a condiciones fácticas como las costumbres, los hábitos sociales ${ }^{15}$, o los regímenes establecidos, tan luego como se suponga que cada cosa factual tiene su propia naturaleza, y por tanto, que el estado de cosas actual sería resultado de un cierto progreso natural que sólo quedaría ser normativamente refrendado. Una perspectiva como ésta comporta naturalizarlo todo; las cosas, los procesos y las instituciones; las costumbres, las formas de vida, los sistemas normativos, la distribución de ventajas, los regímenes político-sociales, con la consecuencia de que se instale un prejuicio conservador a favor de las condiciones existentes.

Sin embargo, no se puede dudar de que en las circunstancias fácticas hay también mucho de artificial; muchas cosas que no emergen naturalmente, sino que han sido creadas por diseño humano, pueden por ello ser compatibles con las condiciones de la naturaleza o pueden no serlo. Esto es algo que lo sabemos mejor ahora, evidentemente, por la envergadura de la crisis ecológica global debida sobre todo a la magnitud del tipo de artificios construidos por el hombre. Por tanto, un punto de vista que quisiera decirnos que todas las condiciones factuales son de por sí naturales, y que de ellas emerge espontáneamente el Derecho natural por excelencia, necesita ser de cualquier modo puesto en duda.

Por lo demás, no resulta innecesario anotar que si tuviéramos que atribuir de por sí calidades de Derecho al estado de cosas factual, el procedimiento iusnaturalista no se distinguiría mucho del positivismo que atribuye la calidad de Derecho a cualquier sistema de normas existentes por el sólo hecho de existir, o ser vigentes. En tal medida ambas posturas serían igualmente reprobables.

\section{BIOLOGÍA Y DERECHO}

Algunos iusnaturalistas han mostrado su inclinación por otorgar a los hechos biológicos alguna significancia en la constitución del Derecho. Una propuesta reciente es, por ejemplo, la de L. ARNHART, desde una perspectiva proclamada darwiniana ${ }^{16}$. Sin embargo se encuentran antecedentes de ello incluso en la Suma Teológica, cuando Tomás se refiere a la correlación de la ley natural y el «orden de las inclinaciones naturales» del hombre, entre las que distingue la «conservación de su propio ser», «la conjunción de los sexos, la educación de los hijos y otras cosas semejantes» ${ }^{17}$.

\footnotetext{
${ }^{15} I d ., 56$.

16 L. ARNHART, Darwinian Natural Right: The Biological Ethics of Human Nature, Albany, State University of New York Press, 1998.

17 Santo Tomás de Aquino, Suma Teológica —Parte I-IIae-, Cuestión 94.
} 
A propósito de este tipo de vínculos entre naturaleza biológica y Derecho, GARZÓN cita la expresión de E. FECHNER: «Cuando el hombre intenta rebelarse contra las leyes de la naturaleza, entra en lucha con los principios a los cuales debe su existencia como hombre. Todo actuar contra la naturaleza tiene que conducir a la propia destrucción». GARZÓN encuentra que esta expresión es similar a algunas de Adolf Hitler, «un hombre que - dice el profesor argentino- también quería encontrar fundamentos biológicos al Derecho» ${ }^{18}$.

GARZÓN parecería sugerirnos así un distanciamiento casi extremo entre Derecho y biología, sosteniendo un punto de vista que contrasta con teorías como la referida de ARNHART, o con puntos de vista que se han propuesto en los últimos años acerca de las relaciones entre biología, Estado y Derecho, por corrientes como las de la sociobiología de E. O. WILSON ${ }^{19}$, o por la denominada bio-política de autores como SOMITPETERSON ${ }^{20}$ y MASTERS ${ }^{21}$.

Por supuesto, tampoco se puede suponer que el Derecho sea sólo una sutil extensión de la biología, pero no se puede descartar que algún tipo de rol performativo puedan jugar las necesidades biológicas, aun cuando fuese sólo como límites naturales a las pretensiones coactivas del Derecho y del Estado. Se plantea entonces la conveniencia de diferenciar entre las afirmaciones que mantendrían que «todo el Derecho es reducible a biología», o «que el Derecho no tiene que hacer nada con la biología», de la que sugiere que determinados aspectos de la biología pueden ser relevantes para el Derecho.

Con esto no estamos diciendo que el camino más plausible para tratar con este problema tenga que ser exactamente el del cómodo punto medio. Lo que aquí se implica es la necesidad de trabajar la adecuación específica entre biología y Derecho en cada uno de los contextos de las civilizaciones culturales, y frente a cada uno de los problemas jurídicos que se suscitan. A este respecto, una gran teoría del Derecho que quiera ser lo menos dogmática posible sólo podría ofrecer promedios teóricos y razones generales, después de lo cual habrá siempre la necesidad de ajustar esta relación en el contexto de las propias prácticas regulativas de cada cultura.

Esto advierte que la tarea de encontrar fundamentos - por lo menos parte de los fundamentos - del Derecho en la biología no puede verse como una idea descabellada. A nuestro modo de ver, el problema sólo emerge cuando se atribuyen a la biología propiedades deterministas, o cuando se aducen como relevantes para el Derecho fundamentos biológicos impertinentes, erróneos o simplemente falsos, como le ocurría al Führer al proclamar que hay alguna razón biológica para suponer que los pueblos arios son una raza o que éstos serían biológicamente superiores a otros pueblos.

Veremos más adelante que en este tema la posición de GARZÓN VALDÉS sufre un cambio de orientación que no puede subestimarse, cuando el profesor conviene en advertirnos que el sistema de necesidades básicas puede ser decisivo para el reconocimiento de los derechos.

\footnotetext{
18 E. GARZÓn VALDÉs, op. cit., 51.

19 E. O. Wilson, Sociobiology: The New Synthesis, Twenty-fifth Anniversary Edition, 2000 (1975).

20 A. Somit, «Biopolitics», British Journal of Political Science, vol. 2, núm. 2, Apr.: 209, 1972.

21 R. MAsters, The Nature of Politics, Yale University Press, 1989.
} 


\section{EL ABISMO SER-DEBER SER}

En medio de todo, la acusación estándar que se le hace al iusnaturalismo, dirigida en particular contra la variante que provisionalmente estamos llamando naturalista, es decir, la que pone el acento en tomar en cuenta la realidad existente como fuente de valor, es que incurre en un error lógico al creer que se puede inferir valoraciones y juicios de deber ser, por tanto regulaciones jurídicas y decisiones, partiendo de la «naturaleza» y de la «esencia» de las cosas existentes.

Dice sobre esto GARZÓN VALDÉS: «Aquí interesa el problema de la inferencia de una conclusión de deber ser a partir de premisas de ser. Lógicamente esto es imposible, ya que nada que no esté contenido en las premisas puede aparecer en la conclusión» ${ }^{22}$. No significa que la realidad sea irrelevante para el Derecho — precisa GARZÓN- porque eso sería negar la importancia que disciplinas como la sociología, la antropología, o la psicología tienen para el Derecho; sino que «la tarea del jurista no reside en determinar lo que es, sino lo que debe ser. Este deber ser presupone un juicio de valor. Y este juicio de valor es una proposición que no puede ser extraída de la realidad de las cosas» ${ }^{23}$. GARZÓn reitera que la ciencia del Derecho sería una ciencia normativa, a diferencia de las ciencias empíricas, y por tanto no tendría que estar basada en hechos. Sin embargo mantiene que una posible conexión de las normas con la realidad se daría a través de las reglas que VON WRIGHT denomina anankásticas ${ }^{24}$.

La separación entre ser y deber ser es argumentada regularmente en el nombre de HumE y sobre la base del dualismo de KANT, cuando se sostiene la imposibilidad lógica de pasar de afirmaciones del ser («es») a afirmaciones de «deber ser», una formulación que Hume trasluce en las páginas de su Tratado sobre la Naturaleza bumana ${ }^{25}$. Decimos «en el nombre» de HumE porque numerosas evidencias indican no sólo que Hume no era enemigo del naturalismo, sino que su filosofía entera es esencialmente naturalista, incluso en el plano de la ética ${ }^{26}$. Es posible que la alusión al famoso párrafo del Tratado se origine en una incomprensión del naturalismo de Hume, o en una extrapolación indebida de las dudas que Hume se plantea en ese lugar. Hume se refiere en el texto a la imposibilidad de hacer derivaciones lógicas entre enunciados que portan información semántica diferente, lo cual, por lo demás, es un típico axioma de la lógica deductiva; pero en modo alguno estuvo interesado en construir una «guillotina» para impedir que la experiencia sea tomada en cuenta al momento de proponer principios morales ${ }^{27}$.

22 E. GARZÓN VALDÉs, op. cit., 55.

${ }^{23} I d$., 65.

${ }^{24}$ Id., 66.

25 D. Hume, A Treatise of Human Nature, Penguin Books, 1985 (1739-1740), 521.

26 Vid. H. Miller, «The Naturalism of Hume», The Philosophical Review, vol. 38, núm. 5 (septiembre 1929): 469-482; N. SmitH, «The Naturalism of Hume», Mind, A Quarterly Review, New Series, núm. 54, abril 1905; J. Kemp, Ethical Naturalism: Hobbes and Hume, MacMillan Press, 1970.

${ }_{27}$ Esto se constata desde el propio subtítulo que HumE adiciona al Tratado: «Being an Attempt to Introduce the Experimental Method of Reasoning Into Moral Subjects»; es decir, un intento de aplicar el método experimental a asuntos morales. 
El argumento de HumE, confundido de corriente con el argumento de la «falacia naturalista» de G. E. MOORE ${ }^{28}$, en combinación con el dualismo kantiano y neokantiano, se halla en la base de la doctrina de la «dualidad fundamental entre ser y deber ser», la cual inspira ostensiblemente a la Teoría pura del Derecho kelseniana. La teoría de KELSEN en tanto positivista está referida al hecho del Derecho existente producido por los hombres, pero en sus orígenes no parece haberse motivado en una reflexión sobre las circunstancias del Derecho tal como éste puede observarse en la realidad, sino en la utilización de la metodología neokantiana que proponía construir las verdades de la ciencia a partir de conceptos sintéticos a priori, originados en la razón pura, valga decir, en las rigurosas elucubraciones del pensador. Desde allí KELSEN pudo avanzar a imaginar el mundo del puro deber ser en el que presuntamente los juicios del científico no tendrían contacto alguno con el ser.

De este modo la metodología neokantiana instala una ruptura no sólo conceptual, sino ontológica entre ser y deber ser, de acuerdo con la cual sólo sería posible razonar normativamente introduciendo presupuestos racionales de deber ser de manera a priori. Con ello se consigue llevar a la práctica el programa de KANT cuando, en la Crítica de la Razón Pura, el gran filósofo racionalista propuso añadir a los juicios sintéticos y analíticos tradicionales de la lógica los juicios sintéticos a priori, que serían los que añaden conocimiento cualitativo aunque no provengan de la experiencia ${ }^{29}$.

Los juicios sintéticos a priori pasan a equipararse a los juicios analíticos en su condición de ser considerados dados en la razón pura, con lo cual el conocimiento de las formas o de los conceptos universales se vuelve a priori. Además, como el deber ser no se puede deducir del ser, entonces hay que presuponerlo; es decir, hay obtenerlo de la cabeza del filósofo, no como una hipótesis a contrastarse por algún medio objetivo, sino como una verdad que se asume demostrada de antemano. Desde allí recién se hace posible derivar un deber ser; desde el deber ser que antes ha sido presupuesto. A continuación la naturaleza se vuelve irrelevante para la moral y el Derecho. Supongamos KANT, por tanto la Teoría pura del Derecho, y a continuación el misterio de la Gründnorm ${ }^{30}$.

La combinación de lecturas, que podríamos suponer poco fieles a la orientación naturalista de la filosofía de HuME, con el apriorismo kantiano, y con las variedades de positivismo lógico subsiguientes, parece haber producido una cierta actitud de subestimación, sino de desdén generalizado, por la realidad empírica, la que ha acompañado a las ciencias sociales, y especialmente a las disciplinas normativas, durante la mayor parte del siglo XX. Esto puede explicar que los saberes del Derecho hayan avanzado de manera poco resuelta en la tarea de reconstruir el vínculo entre ser y deber ser sino hasta épocas muy recientes, acerca de lo cual GARZÓN VALDÉS nos alerta, según se verá

28 Vid. L. SÁNCHEZ, «¿Se origina la falacia en Hume?», Doxa, Cuadernos de Filosofía del Derecho, núm. 30 , 2007, 635-651.

29 I. KANT, Crítica de la razón pura, trad. de M. G. Morente, edición digital basada en la edición de Madrid, Librería General de Victoriano Suárez, 1928, http://www.cervantesvirtual.com (19 de septiembre de 2009), 32-37.

30 En otro lugar hemos sugerido, sin embargo, que a partir de los años cuarenta el kantianismo es menos evidente en el positivismo de KELSEN, aunque el autor mantiene su teoría como Teoría pura. Vid. el artículo, «Sobre el positivismo y la tesis de la separación», en Doxa, Cuadernos de Filosofía del Derecho, núm. 23, Universidad de Alicante, 2002. 
más adelante. A partir de esos desarrollos estaremos mejor posicionados para sostener que los intentos de trazar una valla inseparable entre ser y deber ser pueden considerarse liminarmente desorientados.

\section{DESCRIPTIVISMO}

Se critica también al iusnaturalismo porque reduce la función del legislador a una tarea de conocimiento sin intervención de la voluntad. Esta afirmación es aproximadamente cierta dado que un rasgo común del iusnaturalismo es que presupone la preexistencia del Derecho en cualquiera de las naturalezas previas a que hace referencia, restando sólo describirlo. Sin embargo, en el contexto de la oposición de los teólogos medievales entre intelectualismo y voluntarismo aparece un atisbo de reconocimiento de las posibilidades de la voluntad humana, aunque paradójicamente por el lado de teóricos intelectualistas como Santo Tomas, quien admite la posibilidad de la ley positiva o humana que vendría a ser la expresión de la voluntad del gobernante.

Por el contrario, la acusación de descriptivismo podría afectar al positivismo clásico incluso en mayor medida, desde que el punto de partida de la ciencia positivista es el Derecho puesto por los hombres que al teórico positivista, en principio, sólo le correspondería describir y al operador aplicar. Si el modelo iusnaturalista en cualquiera de sus versiones condenaría al legislador y al intérprete, al menos en teoría, a una pura tarea cognoscitiva, podemos pensar que el positivismo extiende el voluntarismo al legislador pero se lo niega al juez. A menos que a un juez positivista se le permita comportarse en forma no positivista y por tanto se le autorice a introducir sus propios juicios de valor al momento de decidir. O que se sostenga que el enfoque positivista sólo funciona para el teórico de la ciencia del Derecho, pero no para el operador del Derecho. Este último argumento puede ser admisible, pero si ello es así lo que tenemos es que, en la perspectiva del positivismo, aquí no sólo habría una separación de funciones, sino que el punto de vista del científico del Derecho y el del operador entran en colisión. Mientras el científico positivista puede argüir que el Derecho no está inseparablemente unido a una idea moral, el operador judicial podría estar dispuesto a sostener que en la adjudicación del Derecho no se puede partir de aceptar esa separación.

Esto indica que la actitud descriptiva, tanto para el científico como para el operador positivista, debería entenderse como una derivación inevitable del modelo teórico positivista que se reclama inspirado por una vocación de neutralidad científica, semejante a la que se presume en las demás ciencias. Esto podría explicar, al menos parcialmente, que algunos autores positivistas se sientan motivados a sostener que en la interpretación los jueces deberían limitarse a reproducir fielmente los contenidos del Derecho, idealmente sin ningún margen de discreción. En alguna medida esto se implica en exposiciones como las de SCARPELLI, o en el positivismo ético de CAMPBELL, aunque en ambos casos en concurrencia con la idea de una función política del Derecho, en el marco de un Estado liberal que es requerido a mantener una separación nítida entre las funciones legislativa y judicial.

En la práctica, las relaciones entre describir y prescribir, entre aplicar o crear el Derecho, constituyen una tensión permanente en las teorías tanto de KELSEN como 
de HART. Aunque en tanto teóricos del Derecho se muestran partidarios de reconocer como Derecho al Derecho que «es» en las condiciones fácticas, en tanto teóricos del razonamiento jurídico circunstancialmente ambos autores llegan a aceptar que la tarea del juez no puede consistir en un puro descriptivismo, y que en la interpretación hay siempre espacio para la creación judicial. KELSEN llega incluso a sugerir que en los casos de lagunas habría una creación normativa de libre decisión del juez ${ }^{31}$, en tanto que para HART la creación judicial sólo podría darse en los márgenes de la penumbra de las leyes ${ }^{32}$.

En definitiva, si dejamos de lado las tensiones internas en las teorías de los fundadores del positivismo legal y de los varios positivismos que se han intentado a partir de ellos, no resulta exagerado sostener que tanto el iusnaturalismo como el positivismo se identifican metodológicamente en la pretensión final de estar basados en razones puramente descriptivas, o «avaloradas» como a veces se dice. Lo que pensamos varía entre ambas corrientes, es únicamente el Derecho que cada escuela se propone describir. En el caso del iusnaturalismo se tienen por lo menos tres objetos de descripción: el Derecho natural divino, el Derecho natural derivado de la razón humana, y el Derecho natural derivado de las circunstancias naturales del mundo físico. En el caso del positivismo se tiene la variante hartiana que propone describir lo que los operadores dicen que es Derecho de acuerdo con la regla de reconocimiento de cada ordenamiento; y la variante kelseniano-kantiana que propone describir el deber ser, tal cual éste puede ser derivado de la norma fundamental presupuesta.

La posibilidad de creación de valor por la vía del razonamiento judicial, o a través de las prácticas de las comunidades, o por el consenso democrático de los participantes, queda esencialmente fuera de cualquiera de estas posiciones ${ }^{33}$.

\section{JUSTICIA, IDEOLOGÍA Y EMOCIÓN}

6.1. Otra de las críticas que GARZÓN esgrime contra la doctrina de la «naturaleza de la cosa» es que en cierto sentido la naturaleza a la que aluden está vinculada a la idea de justicia, y la justicia la sugiere GARZÓN equiparable a ideología ${ }^{34}$. Una crítica de este estilo se encuentra como sabemos en KELSEN, quien pensaba que la justicia está llamada a operar en los casos de conflictos de valores, los cuales «no pueden resolverse mediante el conocimiento racional». «La respuesta (a esos conflictos)... — dice KELSEN- es siempre un juicio que, en última instancia, está determinado por factores emocionales, ostentando, por consiguiente, un carácter altamente subjetivo» ${ }^{35}$.

31 Vid. H. Kelsen, Teoría pura del Derecho, México, UNAM, 1983 (1960), 357.

32 H. HART, «Positivism and The Separation of Law and Morals», en Harvard Law Review, vol. 71, núm. 4, febrero 1958, 614 .

33 Esto no elimina, por supuesto, los esfuerzos de los positivismos más recientes para dar a la interpretación una característica más hermenéutica o argumentativa, y por tanto reconocer al operador un rol más creativo. Sin embargo, ese esfuerzo no deja de enfrentar dificultades posiblemente insalvables dentro de la matriz de pensamiento positivista en tanto teoría del Derecho, según lo hemos sostenido en otro lado. Vid., del autor, «ंTiene el positivismo aptitud para operar con valores?», en Argumentación jurídica y teoría del Derecho, Arequipa, Ediciones El Alva, 1999.

34 E. GARZÓN VALDÉs, op. cit., 35.

35 H. Kelsen, Qué es la justicia, Ediciones El Aleph, 2000 (1957), 15. 
Subyace, pensamos, en la crítica de GARZÓn como en la de KeLSEN al menos un prejuicio del razonamiento y un presupuesto teórico inexacto. El prejuicio se percibe en la creencia virtual de que la justicia para que sea objetiva debería poder ser reducible a un solo criterio, o a una sola regla, que probablemente las personas deberían ser capaces de reconocer más o menos al unísono para que goce de crédito racional. Es posible que esto pudiese ser realidad en un mundo basado en un solo criterio de estructuración y donde además las personas fuesen idénticas. Pero si el mundo que habitamos es diverso, y las personas, las culturas en las que aquéllas se desenvuelven y las situaciones justiciables son variadas, es razonable suponer que pueda haber también varios criterios de justicia, tan luego como éstos sean apropiados para atender las diferentes situaciones de conflicto. El conflicto de valores no supone, de por sí, una condición de irracionalidad ${ }^{36}$.

El presupuesto teórico inexacto reside, a nuestro modo de ver, en la aceptación, tanto por KELSEN como por GARZÓN, del emotivismo ético propuesto por STEVENSON, como una derivación de los dogmas del positivismo lógico acerca de la naturaleza de la verdad. En la teoría de STEVENSON los valores no tienen existencia objetiva y por tanto no pueden probarse ni verdaderos ni falsos, ni por medios empíricos ni por medios lógicos. Las afirmaciones morales podrían equipararse a simples enunciados de preferencias sentimentales o emotivas sin posibilidad de que sean comparables.

No puede discutirse que los juicios morales sean tratados como enunciados subjetivos en la medida en que son pronunciados por las personas; pero también pueden tratarse como juicios objetivos en la medida en que pueden ser sentidos, y compartidos, por grupos, sino por todas las personas ${ }^{37}$. Evidentemente, los juicios de valor corresponden a las experiencias de vida de la gente y pueden ser equiparables cuando menos sobre la base de la condición biológica equivalente de los individuos y de las vivencias subjetivas que comparten en la satisfacción de sus necesidades y deseos. Esto hace posible, por ejemplo, que dos personas, o digamos varios miles, puedan decir cada una por su lado «tengo hambre», y coincidir en el juicio «es bueno alimentarse»; de la misma manera en que podrían experimentar por separado cada una un asalto, y coincidir luego en el juicio de valor «los asaltos son malos y deben prohibirse». Otro tanto podría decirse de valores como la sinceridad, el amor, la amistad, la honestidad; o avanzando hacia los niveles de valoración política, de la solidaridad, la equidad, la cooperación, la paz, etcétera.

Esto sugiere que el concepto de justicia no ha de ser tan subjetivo, ni tan relativo, ni tan irracional como creía KELSEN. No es éste el lugar para profundizar en tan importante debate, pero vale la pena advertir la eventual responsabilidad de las creencias difundidas por el positivismo lógico, por haber empujado a la teoría jurídica, y en general a los saberes normativos, en una dirección deconstructiva de la racionalidad de los valores que se muestra radicalmente equivocada.

36 Por alguna razón la búsqueda de la respuesta única, o de la verdad única válida para todos los casos — en lugar de pensar en verdades para cada caso_-, sigue siendo una de las tendencias típicas, a menudo inconscientes, del pensamiento moderno. Cuáles sean las razones de esta propensión es algo por explicarse. En respuesta han proliferado los enfoques llamados post modernos que transitan con frecuencia hacia el otro extremo, hacia la creencia de que los criterios de verdad son inexistentes o que sería imposible hacer comparaciones entre juicios de valor.

37 En definitiva, esto no los diferencia radicalmente de la manera en que se constituyen los juicios de las llamadas ciencias, los cuales también requieren un cierto grado de acuerdo subjetivo. 
Sin duda, GARZÓn VALDÉs es consciente de tales excesos, y por eso en sus posiciones más recientes se mantiene claro en afirmar que una teoría que quiera dar cuenta de la manera en que opera el Derecho necesita referirse a alguna clase de moderado objetivismo ético ${ }^{38}$.

6.2. En conexión con lo anterior GARZÓN ha señalado también la carga emotiva que se implica en la doctrina de la «naturaleza de las cosas». Detrás de esta doctrina subyacen expresiones emotivas vinculadas con aspiraciones morales o con creencias en la justicia. «La palabra "naturaleza" — escribe el profesor — tiene un valor emotivo muy grande y no pocas veces alcanza un efecto persuasivo más o menos permanente» ${ }^{39}$. De ese modo GARZÓn se muestra partidario de la pretensión positivista de excluir las emociones de los conceptos, dirigida en este caso contra los intentos de pensar el Derecho en dirección hacia alguna idea de justicia.

Es cierto que hay en la palabra «justicia» una gran carga de emotividad, pero quizás no tan diferente de la que hay cuando pronunciamos otras palabras, por ejemplo la palabra «verdad». Después de todo, la palabra que con mayor emotividad, y fuerza persuasiva, nos ofrecen los autores para justificar sus afirmaciones es la palabra «verdad». La segunda es la palabra «ciencia», a la cual apelan la mayoría de discursos que tratan de ganar prestigio en nuestro tiempo. Por supuesto, ello no ha evitado los innumerables desaciertos, las no pocas mentiras y otro tanto de ilusiones en las que incurre el conocimiento llamado científico que el mundo instrumental ha elevado a la categoría de autoridad suprema.

Tampoco se puede decir que expresiones típicas del positivismo como «seguridad jurídica», «orden público», «validez legal»... estén exentas de alguna connotación emotiva. Todo esto lo sabemos con mayor claridad desde que las teorías del lenguaje nos han mostrado que en todas las expresiones del habla hay siempre una dimensión pragmática inherente dirigida a impactar en el interlocutor, sea ésta de mayor o menor intensidad. Y lo entendemos mejor en la discusión jurídica a partir de teorías como las de R. AleXY que sugiere la imposibilidad analítica de excluir de la definición del Derecho la fuerza de la intención performativa que esta palabra tiene, vale decir, lo que ALEXY llama pretensión de corrección, implícita en el acto de enunciar una Constitución ${ }^{40}$. Puede suponerse luego que en la intención performativa algún grado de emoción ha de concurrir, inevitablemente.

Pensamos que algo parecido se implica en la teoría del profesor GARZÓN cuando nos habla de la pretensión de legitimidad ${ }^{41}$, y de la importancia del coto vedado de la democracia representativa ${ }^{42}$. Aunque el coto vedado no lo plantea GARZÓN en términos de la idea de justicia, sino de la protección de los derechos básicos de las personas, es

38 E. GARZÓN VALDÉS, «Algo más acerca de la relación entre Derecho y moral», en Derecho, ética y política, edición citada, 1992, 333. Vid. también la introducción a Derecho, ética y política, 10.

39 E. GARZÓN VALDÉS, op. cit., 70.

40 R. ALEXY, «Sobre las necesarias relaciones entre Derecho y moral», en Derecho y razón práctica, México D. F., Distribuciones Fontamara, S. A., 1993.

${ }^{41}$ E. GARZÓN VALDÉS, «Algo más acerca de las relaciones entre Derecho y moral», en Derecho, ética y política, edición citada, 327 y ss.

42 E. GARZÓN VALDÉS, «Representación y democracia», en Derecho, ética y política, edición citada, 645. Algo más acerca del «Coto vedado», en Doxa, Cuadernos de Filosofía del Derecho, núm. 6, Universidad de Alicante, 1989, 209-213. 
innegable que se acompaña también de un mensaje emotivo, en la medida de la carga emocional indudable que despierta el afán de protección de los derechos humanos. Esto no significa, por supuesto, que tal carga sea ilegítima, inservible, ni censurable, ni que pueda ser tachada como «anticientífica».

A nuestro modo de ver, el problema no reside tanto en que los conceptos del Derecho - o los de la moral - connoten una cierta intención emotiva, sino en que esas emociones puedan ser compartibles dentro de una comunidad democrática. Es decir, que desde el concepto de Derecho, hasta la constitución práctica del orden jurídico mismo, existe la posibilidad de que las normas jurídicas puedan pensarse ligadas tanto a ideas claras como a bienes valiosos y a sentimientos buenos, tan luego como los participantes se muestren dispuestos a suscribirlos dentro de un contexto de abierta manifestación democrática y de condiciones de aceptabilidad universal.

6.3. GARZÓN se propone también hacer justicia al iusnaturalismo porque habría servido para legitimar el régimen hitleriano, en contra de los autores que aducen que los horrores de ese régimen fueron avalados por el positivismo jurídico. Recuerda el profesor que un autor de la época, H.-H. DiETzE, fundamenta en la naturaleza de la cosa la «necesidad de un Ministerio de Propaganda» y el «principio de la infalibilidad del Führer». Derecho es, según DiETZE, «aquello que los hombres arios consideran que es Derecho, no Derecho (Unrecht) lo que ellos rechazan»; y «la misma sangre exige un mismo Reich» ${ }^{43}$.

No se puede dudar de la crudeza antidemocrática de las expresiones de DiETZE, pero cabría preguntarse si estamos estrictamente ante un argumento iusnaturalista o se trata más bien de una afirmación característica del positivismo legal. Si de acuerdo con el positivismo típico, Derecho es lo que los hombres dicen que es en cada ordenamiento jurídico vigente, con independencia de la orientación moral que las reglas tengan, las declaraciones de DiETZE vendrían a ser típicamente positivistas, sólo que hechas desde su ubicación en un orden jurídico concreto, a saber, el nazi. No elimina esto el que tales afirmaciones se hayan hecho en nombre del Derecho natural. En todo caso se trataría de la proclamación legalista de un «Derecho natural» evidentemente injusto, o de la utilización ideológica de la palabra «natural» legitimada con el soporte del discurso científico positivista.

Esto hace ver que desde el punto de vista teórico, tanto el iusnaturalismo dogmático como el positivismo legalista son propensos a favorecer la legitimación de las dictaduras; sea por la absolutización de una idea sustantiva particular en el primer caso, o por la absolutización de cualquier idea encaramada en el poder, en el segundo.

El problema mayor se presenta por supuesto cuando ambas posiciones se coluden bajo la circunstancia de un régimen injusto, porque mientras uno (el iusnaturalismo) suministraría los contenidos de injusticia, el otro (el positivismo) los convertiría en ley obligatoria por el solo hecho de haberse promulgado o adquirir carácter de obligatoriedad. Es posible que ésta haya sido la combinación letal realmente operando bajo las condiciones del nazismo y de los fascismos europeos, con independencia de la posición personal que pudieron adoptar los diversos autores positivistas o iusnaturalistas en esa deplorable coyuntura.

${ }^{43}$ En E. GARZÓN VALDÉs, «La naturaleza de la cosa», en Derecho, ética y política, edición citada, 43. 
Se advierte entonces, según este razonamiento, que el positivismo puro no opone de por sí ninguna valla a la posibilidad de que ciertas reglas de una alta intensidad dogmática - por ejemplo, las emitidas por una dictadura - puedan ser reconocidas como Derecho. Según el positivismo ortodoxo, la condición para que una norma sea reconocida como Derecho es que sea emitida y que se acepte de obligatorio cumplimiento, tan luego corresponda con una norma fundamental que prescribe cumplir con la Constitución, o con una regla de reconocimiento que puede asumirse identificada por los operadores del régimen vigente. Es decir, que el positivismo no elimina la posibilidad de una dictadura iusnaturalista, como ilustra el ejemplo de la Alemania nazi, aunque esta consecuencia pueda sonar paradójica. En verdad, en el seno del positivismo legal hay la posibilidad de todas las dictaduras. Esto lo sabemos, entre otros, por declaración del propio KELSEN, quien en 1925 había dicho:

«No tiene sentido afirmar que en el despotismo no existe ningún orden jurídico sino que tan sólo domina la arbitrariedad del déspota [...] El Estado regido despóticamente también representa un orden de la conducta humana. Este orden es precisamente un orden jurídico. Negarle el carácter de Derecho es sólo una ingenuidad iusnaturalista [...] Lo que es interpretado como arbitrariedad es sólo la posibilidad del autócrata de poder tomar cualquier decisión [...] y suprimir normas establecidas [...]» ${ }^{44}$.

Y en 1963 volvió a reiterarlo:

«Desde el punto de vista de la ciencia del Derecho, el Derecho durante el dominio nazi es Derecho. Podemos lamentarlo, pero no negar que fue Derecho».

En otros términos, si se piensa el Derecho sólo como un orden coactivo u obligatorio de la conducta, con independencia de su origen y de su orientación valorativa, no se evidencia entonces una correlación necesaria entre positivismo y democracia. No resulta fácil sumar teóricamente la idea democrática dentro de la definición positivista de Derecho - aun cuando así suceda en la práctica y aun cuando la democracia sea el régimen favorito de los autores positivistas- porque entonces estos autores se verían impelidos a tener que admitir que hay al menos un valor que precede al Derecho positivista y que el legislador no puede violentar: la libertad de discusión y formación democrática del consenso normativo ${ }^{45}$. Se tendría entonces que definir el Derecho, en términos del positivismo, como «cualquier orden de la conducta compuesto de normas obligatorias que los operadores aplican, siempre que sus orígenes sean democráticos». Con esto se avanzaría bastante desde luego, pero esto ya no suena estrictamente al positivismo que estamos acostumbrados, cuando menos en la versión de sus dos principales representantes, KELSEN y HART. En ninguno de estos dos autores se advierte la intención de avanzar hacia una teoría que vincule orgánicamente el Derecho con la teoría de la democracia ${ }^{46}$, por lo menos en tanto teóricos del Derecho.

44 Id., 62.

45 Esta paradoja de hecho se halla presente en KELSEN, quien, a juicio de GARZÓN, necesita presuponer las ideas de libertad e igualdad como condición para su defensa de la democracia. KELSEN, que se afirma avalorado en el campo del Derecho, en el campo de la democracia no puede sino apelar a los presupuestos sustantivos de libertad e igualdad, debido a lo cual GARZÓN sugiere que la idea del coto vedado de la democracia tendría ya algún antecedente en el ensayo Esencia y valor de la democracia, del demócrata de Viena. E. GARZÓN VALDÉS, «Representación y democracia», en Derecho, ética y política, edición citada, 640 y ss.

${ }^{46}$ La idea de la que la teoría del Derecho se vincula en KELSEN con una teoría constitucional de la democracia es también puesta en duda por A. PINTORE, «Democracia sin derechos, en torno al Kelsen democrático», en Doxa, Cuadernos de Filosofía del Derecho, 2000, 135. 
Claro está que ni a KELSEN ni a HART, en tanto pensadores políticos, se les puede negar sus credenciales democráticas. KELSEN parece haber sido un firme partidario de la democracia desde los años inmediatos a la República de Weimar, democracia que justifica, más adelante, entre otras razones por considerar que es un contexto político compatible con el relativismo axiológico del cual parte ${ }^{47}$. En el caso de HART, su identificación democrática proviene no sólo de la tradición cultural en la cual trabaja, sino de la postura socialdemocrática que fue característica de su vida. En sus últimos trabajos mostró además una preocupación genuina por los problemas de la razón práctica, así como por las ideas de la democracia como deliberación. Lo sorprendente es que en ninguno de los dos autores las reglas de la democracia juegan rol alguno como fundamento de las reglas del Derecho.

\section{NATURALISMO, CIENCIA Y POSITIVISMO}

7.1. Un balance de lo hasta aquí dicho advierte que la mayoría de las críticas reseñadas en diálogo con las ideas del profesor GARZÓN afectan sobre todo al iusnaturalismo escolástico y al racionalista, pero quizás no todas —en particular las críticas de absolutismo, esencialismo, apriorismo, inmutabilidad y pensamiento metafísicoal iusnaturalismo que por ahora hemos llamado naturalista, aunque algunos podrían cuestionar que éste sea un verdadero iusnaturalismo en el sentido de la tradición descrita como clásica ${ }^{48}$.

Se podría pensar, entonces, que tan luego como el Derecho natural se despoja de sus ataduras teológicas y racionalistas, y se admite que la naturaleza real cuenta para el Derecho, hablar de un cierto «Derecho natural» se vuelve más comprensible, y si se prefiere, se vuelve más «científico», por la posibilidad de que las razones de un tal Derecho puedan ser discutidas sobre la base de algún tipo de hechos de cierta objetividad.

Esta posible aproximación del discurso iusnaturalista al modelo de legitimación de las ciencias no sería del todo infructuosa y puede ser singularmente persuasiva en términos del discurso al que el positivismo apela regularmente para legitimarse. Después de todo, los ataques que el positivismo dirige contra el iusnaturalismo se hacen regularmente en nombre de «la ciencia», o por exigencias «científicas»; vale decir, desde el prestigio de la palabra «ciencia», y desde la perspectiva de una ciencia que se reclama descriptiva y neutral a los valores. Sin embargo, pensamos que el positivismo proyecta una mirada oblicua sobre la realidad y alcanza una imagen incompleta acerca de la constitución del mundo jurídico.

Por un lado el modelo de ciencia jurídica positivista no describe todo lo que realmente existe en los hechos que conforman lo jurídico. No percibe, por ejemplo, que

47 Id., 120 y ss.

48 EÉste viene a ser, por ejemplo, el punto de vista de P. D'EnTREVES, para quien «La noción de Derecho natural... se refiere a la conducta humana, no a fenómenos físicos». A. P. D’ENTREVES, op. cit., Introducción. Circunstancialmente, en su réplica a KELSEN, BODENHEIMER arguye lo contrario. Según este autor, el punto de partida general del Derecho natural sería la «... consideración de ciertos rasgos y necesidades básicas de los seres humanos, que las leyes no pueden ignorar ni disponer». E. BODENHEIMER, «The Natural-Law Doctrine Before the Tribunal of Science: A Reply To Hans Kelsen», Political Research Quarterly, 1950, $3,336$. 
cualquier norma es impronunciable sin algún tipo de elección valorativa. Esto hace que las normas estén siempre unidas a algún tipo de valoración, o si se quiere, que los valores permeen todo el entramado normativo. Por esa razón, han de apreciarse como acertadas opiniones como las de ATIENZA y RUIZ MANERO cuando sostienen que en toda norma hay siempre un elemento valorativo, además de un elemento directivo ${ }^{49}$; o un elemento deóntico y otro ideológico, como escribe Ó. CORREAS ${ }^{50}$.

Además, los valores se encuentran no sólo en los enunciados normativos que pronuncian el legislador o el dogmático del Derecho, sino también en las prácticas de todos los operadores del orden jurídico, y por supuesto en las vivencias y expectativas de la gente; aun cuando éstos no sean fotografiables, ni se puedan reproducir en el laboratorio, o no se puedan describir a la manera en que un biólogo describe los peces de una laguna, o un geólogo las rocas. Si ésa es la manera en que el positivismo científico esperaría que se pueda probar la existencia de los valores, entonces la falla podría estar en el científico.

Por otro lado, el positivismo típico parece admitir como única lógica de la ciencia, y por tanto como criterio infalible de verdad, la lógica deductiva. Esto puede explicar la facilidad con que los teóricos positivistas acceden al argumento de la «falacia naturalista» erigido para oponer una valla entre la experiencia y el conocimiento. Por tanto, como la lógica deductiva no autoriza a pasar lógicamente del ser al deber ser, ni de la realidad al concepto, el ser no cuenta y la naturaleza es declarada irrelevante para las circunstancias del Derecho.

El infundado temor que el positivismo, en este caso principalmente de la línea kelseniana, según creemos, ha desarrollado frente al argumento de la falacia de G. E. MOORE, introduce además el sesgo de considerar al Derecho tanto más científico en tanto pueda presumirse que es más lógico. Esto quizás da algunas pistas para explicar el esforzado camino que han seguido notables pensadores por los caminos del formalismo y de la lógica jurídica, en la búsqueda de una lógica deóntica estricta. Una suerte de piedra iusfilosofal que serviría para probar la eminente cientificidad del Derecho, y por tanto la rigurosa calculabilidad que podría alcanzar el razonamiento jurídico ${ }^{51}$.

Adicionalmente, el modelo positivista de ciencia jurídica no admite que el acto de describir el Derecho envuelve también una pretensión normativa fuerte, a diferencia de las pretensiones débiles unidas, por lo general, a los enunciados de las ciencias naturales.

Cuando un naturalista describe una variedad de planta, por ejemplo esa que en el Perú llamamos «yerbabuena», podemos creer que su intención es simplemente «describir», con la mayor objetividad, los atributos de la planta tal cual son; aunque no dejarán de haber al menos dos mensajes performativos en los enunciados «descriptivos» que el investigador emita: primero que aceptemos el nombre de la planta que describe

49 M. Atienza y J. R. MAnero, Las piezas del Derecho. Teoría de los enunciados jurídicos, Barcelona, Ariel, $1996,123-124$.

${ }_{50}$ Vid. Ó. CORREAS, Crítica de la ideología jurídica, México D. F., UNAM, 1993.

51 Vid. C. Alchourrón y E. Buligyn, «Limits of Logic and Legal Reasoning», en A. Martino (ed.), Experts Systems in Law, Elsevier Science Publishers B. V., 1992; G. H. vON WRIGHT, «Is There a Logic of Norms?», en A. ARNIO y N. MACCormick, Legal Reasoning, vol. I, England, Darmouth, 1992, 396. 
— por ejemplo si la presenta como una variedad de menta-; segundo, que creamos que lo que él afirma acerca de la planta debe ser asumido como verdad demostrable, dado que muy pocos de los oyentes tendrían la posibilidad, y el interés, de verificar esos datos por sí mismos.

Un jurista hace algo parecido cuando, motivado por un «puro» interés «científico» se propone describir el Derecho a partir de las propiedades normativas comunes que puede encontrar entre los órdenes jurídicos que compara, sólo que aquí concurre una intención performativa más fuerte. Desde que el Derecho está imbricado de valores - como lo está la persona que describe-, expresa o tácitamente el jurista nos está dando un juicio de valor junto con las descripciones del orden que contempla. Nos propone, por tanto, que aceptemos el Derecho, tal cual él lo describe, o lo caracteriza, y que asumamos también que ése es el Derecho que debería ser en adelante, aunque lo presenta como un resultado natural predeterminado, a la manera de una planta, como si éste no fuese producto humano. Es decir, que el acto descriptivo de la «ciencia jurídica» es también un acto performativo de la orientación sustantiva del Derecho, a diferencia del acto descriptivo del naturalista que sólo performa el nombre y quizás la clasificación que decidirá darle a la variedad que investiga. El jurista «científico» contribuye de este modo a performar el Derecho que será entendido, asumido y puesto en práctica por la comunidad política. Afirma por tanto una dirección normativa espontánea que contribuye a la formación del Derecho vigente.

Sin olvidar, además, que el Derecho que el jurista «científico» describe es, en última instancia, el resultado de innumerables voluntades performativas pasadas.

7.2. Aparte de estos argumentos que pueden dirigirse contra las corrientes centrales del positivismo jurídico, hay otros que podrían añadirse en conexión con la definición avalorada que ofrece del Derecho, reduciéndolo en última instancia a un orden coactivo vigente de la conducta del cual se derivan las reglas válidas. Si se acepta que éstas vienen a ser las notas distintivas del Derecho, sin importar si las reglas son acordadas por la gente o proceden de órdenes impuestas por poderes fácticos autoritarios, entonces surge aquí una dificultad importante para las distinciones que tanto KELSEN como HART hacen entre un orden jurídico y un orden de bandidos.

En las páginas iniciales de la Teoría pura, KELSEN parte de hacer esta distinción ${ }^{52}$. El orden de bandidos se basa en la imposición de una amenaza; el orden jurídico en que la amenaza es el resultado de la aplicación de una norma. Es decir que en el orden jurídico se presupone una norma fundamental que es la que da validez a las normas y a las amenazas basadas en ella. Esto no ocurre en el régimen de los bandidos:

«¿Por qué no se presupone una norma fundante semejante?» en este caso, se pregunta KELSEN, «No se la presupone... cuando ese orden (el de los bandidos) no tiene una efectividad duradera sin la cual no se presupondría una norma fundante a él referida, que sea fundamento de su validez objetiva...». «Claramente — añade KELSEN— carece de esa efectividad (el orden de los bandidos)... cuando el orden coactivo, considerado como orden jurídico, es más efectivo que el orden coactivo constituido de la banda de ladrones» ${ }^{53}$ (cursiva añadida).

52 H. Kelsen, Teoría pura del Derecho, edición citada, 57-63.

${ }^{53} I d ., 60-61$. 
Esto querría decir, de acuerdo con las expresiones de KELSEN — si seguimos la traducción ofrecida por VERNENGO- que la diferencia entre el Derecho y el orden de un grupo de bandidos sería sólo una cuestión de efectividad, o de duración en el espacio y el tiempo. En teoría, un orden de bandidos podría ser admitido como orden jurídico tan luego como su «efectividad» en el tiempo, y en el espacio, sea mayor al de un orden jurídico. ¿Sería éste el caso de una dictadura corrupta que mediante la violencia o el ardid se mantiene varios años en el poder? Pero, entonces, ¿existe realmente una diferencia cualitativa — valdría decir conceptual - entre el orden jurídico y un orden de bandidos en la teoría de KELSEN, o la diferencia es sólo un asunto de extensión del poder fáctico y por tanto de la capacidad que tengan uno u otro régimen para mantenerse efectivos en el tiempo? ¿Es esto lo que KELSEN — partidario indiscutible de la democracia- quiere realmente decir?

La dificultad es semejante para la teoría de HART, aunque HART no necesita presuponer la existencia lógica de una tal norma fundamental, sino que la da por hecho, es decir, la presupone en la práctica. A diferencia de un asaltante que da órdenes a un oficinista para que le entregue el dinero, las normas jurídicas tienen en grado preeminente esta característica de «permanencia» o persistencia, dice HART ${ }^{54}$. De ahí que «...si hemos de usar la noción de órdenes respaldadas por amenazas como explicatoria de lo que son las normas jurídicas, tenemos que tratar de reproducir este carácter de perdurabilidad que ellas exhiben ${ }^{55}$. Evidentemente se trata de un punto de vista equivalente al de KELSEN, que hace descansar la validez ultimadamente en la efectividad del ordenamiento; aunque KELSEN añade a ello un argumento de presunción neokantiana a favor de la norma fundamental, mientras HART asume que la validez se da en correspondencia con la regla de reconocimiento que la da por aceptada como condición de hecho.

Pero la teoría de HART se complica algo más porque el ilustre ex profesor de Oxford considera que «la característica general más destacada del Derecho, en todo tiempo y lugar, es que su existencia significa que ciertos tipos de conducta humana no son ya optativos sino obligatorios, en algún sentido» ${ }^{56}$. HART no podría sostener que esa obligatoriedad se debe a la fuerza del mandato o de la voluntad de quien emite la norma, porque eso lo devolvería al punto de vista de Austin que él está interesado en corregir. Es entonces cuando la noción de punto de vista interno, ligado al comportamiento de los participantes, gana énfasis en su teoría.

«Quienes aceptan la autoridad de un sistema jurídico — dice el pensador inglés- lo ven desde el punto de vista interno, y expresan su apreciación de las exigencias de aquél en enunciados internos, acuñados en el lenguaje normativo que es común al Derecho y a la moral: "Yo (tú) debo (debes)"; "yo (él) tengo que (tiene que)"; "yo (ellos) tengo (tienen) una obligación"»"

Con independencia de que el juicio interno de aceptación del Derecho sea moral o no - cosa que HART niega de plano-, lo importante del punto de vista hartiano, a nuestro modo de ver, es que hace depender la obligación de seguir el Derecho no del

\footnotetext{
${ }^{54}$ H. HART, El concepto de Derecho, edición citada, 29.

55 Id., 29, 30. Cursiva añadida.

56 Id., 7.

57 Id., 249.
} 
hecho de que haya un mandato cuyo incumplimiento está amenazado con una sanción — como fue más propenso a pensar KELSEN-, sino de la posibilidad de que los participantes puedan aceptar la norma como obligatoria, sea por razones morales, utilitarias, o de cualquier otro tipo. Esto lo dice HART de manera más clara:

«La existencia de un sistema jurídico implica las actitudes y la conducta que van involucradas en la aceptación voluntaria de reglas, y también las actitudes y la conducta, más simples, involucradas en la mera obediencia o aquiescencia. De aquí que una sociedad en la que hay Derecho está compuesta por aquellos que ven sus reglas desde el punto de vista interno como pautas o criterios de conducta aceptados, y no meramente como predicciones dignas de confianza de lo que los funcionarios les harán si desobedecen» ${ }^{58}$ (cursiva añadida).

Habría que decir entonces que la obligación jurídica depende de ese reconocimiento interno, condición que no concurre bajo el mandato de una banda de ladrones, ¿Cómo entonces aceptar que la diferencia última entre un orden de bandidos y el orden jurídico es sólo un asunto de «perdurabilidad»?

Las aproximaciones de KELSEN y HART a la definición del Derecho no están, por consiguiente, exentas de consecuencias extrañas:

«Si la definición del Derecho se la quiere referir a que éste constituiría un conjunto de normas que regulan conductas, de seguro no habría una distinción clara con las normas consideradas éticas.

Si la diferencia se la quiere encontrar sólo en el carácter obligatorio de las normas vigentes, se plantea el problema de si hay alguna diferencia neta entre el Derecho de un lado y el ejercicio del poder y la violencia del otro. Téngase en cuenta que el grupo enquistado con frecuencia puede hacer uso de alguna fraseología normativa para imponer su voluntad como ocurrió durante los años del nazismo, y ocurre a menudo durante las dictaduras.

Si tenemos que aceptar — como resulta más persuasivo— que el orden jurídico se reconoce por la obligatoriedad debida al reconocimiento voluntario que los participantes hacen de la autoridad del Derecho, nos acercamos al punto de vista interno de HART, y por este camino se abre la posibilidad de transitar hacia a una comprensión democrática del Derecho. Creemos, sin embargo, que HART no termina de transitar este camino, entre otras cosas porque ese reconocimiento sólo queda al alcance de los operadores y no de todos los miembros de la comunidad política. La Regla de Reconocimiento no surge necesariamente del consenso democrático. En adición, lo primero que resulta sorprendente - como lo advierten varios autores, entre ellos MACCORMICK - es que del punto de vista interno tengan que ser excluidos los significados morales que los participantes podrían eventualmente reconocer en el Derecho ${ }^{59}$, como se sugiere en The Concept of Law».

\section{RESUSTANTIVANDO EL DERECHO: EL PAPEL DE LAS NECESIDADES BÁSICAS}

La discusión precedente ha tratado de mostrar las objeciones invencibles que pueden hacerse tanto a las versiones clásicas del iusnaturalismo como a las del positivismo jurídico. Sin embargo, se sugiere que al menos una variante tradicionalmente implica-

$58 \mathrm{Ibid}$. En el mismo lugar HART añade que la sociedad también «... está compuesta por aquellos a quienes, ya sea porque son malhechores, ya porque son simples víctimas. inermes del sistema, estas pautas jurídicas tienen que serles impuestas por la fuerza o mediante amenazas de fuerza». Sin embargo, éste parece más bien un criterio contingente de adhesión a las normas, dado que no es creíble que los delincuentes se adhieran a la sociedad porque saben que serán castigados, ni las víctimas porque saben que serán víctimas.

59 Vid. E. GARZÓN VALDÉs, Derecho, ética y política, Introducción, edición citada, 11. 
da en el Derecho natural, llamada por el momento naturalista, parecería tener aptitud para resistir varios de los argumentos que se dirigen contra ambas corrientes. Este punto de vista se implica, pensamos en la propuesta más reciente del profesor GARZÓN VALDÉS en torno al papel que jugarían las necesidades básicas en el establecimiento, y justificación, de los derechos; aunque vale anotar que el profesor no usa la expresión «naturalismo» ni podría estar dispuesto a asumir su punto de vista como una aproximación a variedad alguna de Derecho natural.

Una de las cosas que GARZÓN se siente más inclinado a pensar en los últimos años es que si bien no hay identidad entre ser y deber ser, hay cuando menos la posibilidad de construir un puente entre ambos mundos ${ }^{60}$. Es por eso que nos propone ahora pensar en consonancia con la teoría ética de M. BuNGE, y admitir que las necesidades básicas, relacionadas con las posibilidades de realización de un plan de vida, «son la fuente de derechos y deberes morales» ${ }^{61}$. Las necesidades tienen, en consecuencia, algún rol en la constitución de los derechos morales, y a continuación en la legitimidad de los sistemas políticos. «Un sistema político — dice- posee legitimidad cuando ofrece la posibilidad de satisfacer las necesidades básicas y los deseos legítimos de sus miembros» ${ }^{62}$. Por esta vía, se abre la posibilidad de que las necesidades biológicas puedan pasar a ser tomadas en cuenta también en la configuración sustantiva de las normas del ordenamiento jurídico.

Antes ya hemos mencionado que éste no es un punto de vista extraño a las discusiones en la filosofía y teoría del Derecho, posiblemente desde la época antigua. Reaparece incluso en el contexto de un positivismo tan bien logrado como el de HART, cuando el autor concede la posibilidad de un «contenido mínimo de Derecho natural» que estaría presente en cualquier ordenamiento jurídico y que vincula esencialmente con las necesidades de la supervivencia humana. Como sabemos, esta idea la toma HART de autores como HOBBES y HUME, quienes a decir del autor inglés «han visto en el modesto propósito de supervivencia el elemento central indiscutible que da buen sentido empírico a la terminología del Derecho natural» ${ }^{63}$.

De la idea de derechos morales relacionados con las necesidades básicas, GARZÓN camina luego a proponernos que la justificación de la democracia representativa es posible si se acepta la existencia de lo que ha llamado el coto vedado de la democracia. Y precisamente el coto vedado vendría a ser el conjunto de derechos que se derivan del sistema de necesidades básicas o primarias ${ }^{64}$. La particularidad del coto vedado - como se desprende del propio término que GARZón emplea- es que resultaría invulnerable al juego de acuerdos y negociaciones de los parlamentos democráticos, así como a las pretensiones del mercado.

El resultado general de este razonamiento será que, en la teoría de GARZÓN, se aprueba el reingreso de criterios sustantivos que sirven de orientación para el sistema

${ }^{60}$ E. GARZÓN VALDÉS, «Necesidades básicas, deseos legítimos y legitimidad política en la concepción de Mario Bunge», en Derecho, ética y política, edición citada, 422.

${ }^{61} I d ., 422,423$.

${ }_{62}$ Id., $433,434$.

63 H. HART, op. cit., 237, 238.

${ }^{64}$ E. GARZÓN VALDÉS, Necesidades básicas..., loc. cit., 432; «Representación y democracia», en Derecho, democracia y política, edición citada, 645-650. 
político, y por esa vía inevitablemente para los otros componentes de la razón práctica. Recién a partir del reconocimiento del coto vedado, se puede justificar éticamente la representación parlamentaria, cuando ésta respeta «los derechos de cada cual a los bienes primarios... y procura satisfacer... los deseos secundarios de los miembros de una comunidad política» ${ }^{65}$. GARZÓN justifica esta resustanciación de la política por necesidades éticas ${ }^{66}$, pero podría entenderse que en su argumentación se implican también razones conceptuales, posiblemente vinculadas al principio de la mayoría que GARZÓN, siguiendo a KELSEN, entiende como un principio definitorio de los regímenes democráticos ${ }^{67}$. El profesor avanza incluso más, y propone la existencia de una conexión conceptual entre Derecho y moral, añadiendo que hay cada vez una «estrecha relación entre el Derecho, la ética y la filosofía política» ${ }^{6}$, un punto de vista que confluye en la tarea de resustantivar el Derecho con teorías recientes como las de la argumentación racional y las del neoconstitucionalismo.

Aunque GARZÓN parece optar por una típica instancia kantiana, al defender la reaparición de valores morales en el ordenamiento jurídico-democrático ante todo por necesidades éticas, hay que remarcar que se trata de valores ultimadamente reconocidos en su conexión con el sistema de necesidades básicas de las personas. Esto viene a afirmar la importante consecuencia de que la naturaleza, y concretamente la biología de los individuos, no es indiferente para las elaboraciones normativas. Las teorías del Derecho y de la democracia no pueden pensarse tan separadas de ciertos hechos de la naturaleza. Independientemente de que esto quiera verse, o no, como retorno a un cierto iusnaturalismo - discusión que no tiene auténtica prioridad-, un punto de vista como éste tiene, a nuestro juicio, gran potencial renovador en el Derecho en procura de lograr un diálogo más coherente entre el Derecho y la vida. Bien valdrá la pena retornar sobre ello en otro momento.

65 Id., 649.

66 E. GARZÓn VALDÉs, Representación y democracia, loc. cit., 644.

67 Id., 637.

68 E. GARZÓN VALDÉs, «Algo más acerca de la relación entre Derecho y moral», en Derecho, ética y política, edición citada, 324. También la Introducción a esta última obra, 11. 